\title{
Chromosome aberrations and sister chromatid exchanges (SCEs) in peripheral blood lymphocyte cultures of untreated leprosy patients
}

\author{
DORIS D'SOUZA \& I M THOMAS \\ Division of Human Genetics, Department of Anatomy, St John's \\ Medical College, Bangalore-560 034, India
}

\section{Accepted for publication 6 December 1987}

\begin{abstract}
Summary The frequencies of various chromsome aberrations and sister chromatid exchanges (SCEs) were studied in blood lymphocyte cultures of untreated leprosy patients. The frequency of chromosome aberrations was significantly higher in lepromatous $(P<0.001)$ and tuberculoid $(P<0.02)$ groups in comparison with that of controls. The frequency of SCEs was found to be within normal range in the tuberculoid group whereas in lepromatous group, a significant $(P<0.001)$ increase was observed. The findings indicate a probable correlation between the form of leprosy and chromosome damage.
\end{abstract}

\section{Introduction}

A variety of physical and chemical agents as well as living organisms like viruses are known to cause chromosome aberrations, ${ }^{1-4}$ and also to induce SCEs. ${ }^{5-7}$ There is however, very little information on the relationship between bacterial infections and chromosomal aberrations. In spite of the worldwide incidence of leprosy, which is a chronic bacterial disease caused by Mycobacterium leprae, there is as yet no report of its eff ects on the genome of the patient. The in vitro and in vivo studies of the effect of antileprosy drug(s) that have been carried out, ${ }^{8-10}$ have not ruled out the role of $M$. leprae as an additional clastogenic agent. The present study has, therefore, been designed to assess the effects of $M$. leprae in causing chromosomal damage in lymphocyte cultures of untreated leprosy patients. Further, the frequencies of SCEs and chromosome aberrations in different types of leprosy have also been studied.

In our heterogeneous lymphocyte cultures, we have utilized just sufficient concentration of 5Bromodeoxyuridine (BrdU $5 \mu \mathrm{g} / \mathrm{ml}$ ), needed to make sister chromatid differention observable ${ }^{11}$ as it is extremely important in chromosome mutation studies to use the minimal concentration of the thymidine analogue so that the level of SCEs is kept at its minimum. ${ }^{12}$

\section{Materials and methods}

PATIENT SELECTION

The patients selected were classified by clinical symptoms and bacterial index (BI) according to the Ridley-Jopling scale. ${ }^{13}$ The tuberculoid leprosy (TT) and the borderline tuberculoid leprosy (BT) 
patients were included in the paucibacillary group. The borderline lepromatous (BL) and the lepromatous leprosy (LL) patients were considered under the multibacillary group.

Both groups consisted of 10 patients each, the paucibacillary group of four females and six males (age range 12-55 years), and the multibacillary group of one female and nine males (age range 32-65 years). These patients had been carefully selected after ascertaining that they had never undergone treatment for leprosy and apparently had no other disease. Ten age-and-sex-matched normal individuals served as controls. These individuals had had no medication and had not suffered from any viral infections in the immediate 3 months prior to this investigation.

\section{LYMPHOCYTE CULTURES}

Peripheral blood lymphocyte cultures were set up according to the method of Arakaki and Sparkes ${ }^{14}$ with slight modifications. Heparinized whole blood $(0 \cdot 3 \mathrm{ml})$ was added to $5 \mathrm{ml}$ of culture medium (TC 199, GIBCO, USA) supplemented with $20 \%$ heat inactivated human AB serum, phytohemagglutinin (PHA: DIFCO M) and antibiotics (penicillin and streptomycin). 5-Bromodeoxyuridine (BrdU, Sigma, USA) was added at the final concentration of $5 \mu \mathrm{g} / \mathrm{ml}$ at the time of culture initiation and the cultures were grown at $37^{\circ} \mathrm{C}$ for $48 \mathrm{~h}$ and $72 \mathrm{~h}$ for analysis of aberrations and SCEs respectively. The cultures were protected from light exposure during incubation. To arrest cells at metaphase, $4 \mu \mathrm{g} / \mathrm{ml}$ colchicine was added to the cultures $2 \mathrm{~h}$ before harvesting. The cells were treated with hypotonic solution $(0.075 \mathrm{M} \mathrm{KCl})$ and fixed in $3: 1$ methanol-acetic acid. Heat-dried chromosome preparations were stained with the Hoechst-Sunlight-Giemsa method. ${ }^{15,16}$ In order to have a correct estimate of aberrations, it is essential to score aberrations only in first division cells. ${ }^{17}$ The use of 5-Bromodeoxyuridine (BrdU) - labelling and Hoechst-Sunlight-Giemsa staining in this study enabled us to select only first division cells. One hundred first cycle metaphases from each subject were scored for spontaneous chromosome aberrations. ISCN $1978^{18}$ criteria were used for the identification and quantification of various types of chromosomal aberrations. Twenty to fifty second cycle metaphases from cultures grown for $72 \mathrm{~h}$ were scored for SCEs from every subject.

\section{Results}

\section{CHROMOSOME ABERRATIONS}

Variations in the frequency of aberrant metaphases were found in different individuals within the same group. In the paucibacillary group, the range of aberrant metaphases were $2-13 \%, 2-6 \%$ in 8 patients, while 2 patients showed a large increase $(13 \%)$. In the multibacillary group, the percentage of aberrant metaphases ranged from 4 to $13 \% ; 4$ to $8 \%$ in $7,10 \%$ in 2 and $13 \%$ in 1 patient.

Controls, in contrast, had a low frequency of aberrant metaphases ranging from 1 to $3 \%$ only. The difference in the frequency of aberrant metaphases was found to be significant $(P<0.02)$ in the paucibacillary group and highly significant $(P<0.001)$ in the multibacillary group when compared with that of controls. The incidence of chromatid gaps and breaks was found to be highest in the multibacillary group and lowest in the control group. Chromosome aberrations other than breaks and gaps were found in low frequency (see Table 1).

\section{SISTER CHROMATID EXCHANGES (SECS)}

The results obtained are presented in Table 2. The frequency of SCEs in blood lymphocytes of the untreated paucibacillary group was $7 \cdot 82 \pm 0.98$ which is comparable to the normal range of SCEs $(7 \cdot 16 \pm 0 \cdot 69)$ observed in controls. In the multibacillary group, a significantly higher $(P<0 \cdot 001)$ frequency of SCEs was obtained (11.04 $\pm 1 \cdot 76)$. 
Table 1. Frequency of chromosomal aberrations in lymphocytes of untreated leprosy patients and controls

\begin{tabular}{|c|c|c|c|c|c|c|c|c|}
\hline \multirow[b]{2}{*}{ Category } & \multirow{2}{*}{$\begin{array}{c}\text { No. of } \\
\text { subjects/ } \\
\text { metphases }\end{array}$} & \multirow{2}{*}{$\begin{array}{c}\text { Abnormal } \\
\text { metaphases } \\
(\%)\end{array}$} & \multirow[b]{2}{*}{$\pm \mathrm{SD}$} & \multicolumn{2}{|c|}{ Breaks } & \multicolumn{2}{|c|}{ Gaps } & \multirow{2}{*}{$\begin{array}{c}\text { Other } \\
\text { aberrations } \\
(\%)^{*}\end{array}$} \\
\hline & & & & Csb (\%) & Ctb (\%) & Csg (\%) & $\operatorname{Ctg}(\%)$ & \\
\hline Paucibacillary & $10 / 1000$ & $5.7 \dagger$ & \pm 4.00 & - & $1 \cdot 2$ & $1 \cdot 0$ & $2 \cdot 8$ & $1 \cdot 8$ \\
\hline Multibacillary & $10 / 1000$ & $7 \cdot 7 \ddagger$ & \pm 2.62 & - & $1 \cdot 7$ & $2 \cdot 5$ & $3 \cdot 9$ & $2 \cdot 0$ \\
\hline Controls & $10 / 1000$ & $2 \cdot 3$ & \pm 0.67 & - & $0 \cdot 4$ & $0 \cdot 0$ & 1.9 & $0 \cdot 2$ \\
\hline
\end{tabular}

Csb, chromosome break; Ctb, chromatid break; Csg, chromosome gap; Ctg, chromatid gap.

* Others include acentric fragments, dicentric chromosomes, double minutes, terminal chromatid deletions, chromatid exchanges and metaphases with a few decondensed chromosomes.

$\dagger$ Significant in Student's 't' test $P<0 \cdot 02$.

$\ddagger$ Significant in Student's 't' test $P<0 \cdot 001$.

Table 2. Frequencies of sister-chromatid exchanges (SCEs) in lymphocytes of untreated leprosy patients and controls

\begin{tabular}{lccrr}
\hline Category & $\begin{array}{c}\text { No. of } \\
\text { individuals } \\
\text { studied }\end{array}$ & $\begin{array}{c}\text { No. of } \\
\text { cells } \\
\text { analysed }\end{array}$ & $\begin{array}{c}\text { SCEs/cell } \\
\pm \text { SD }\end{array}$ & $\begin{array}{c}\text { Range } \\
\text { of SCEs }\end{array}$ \\
\hline $\begin{array}{l}\text { Paucibacillary } \\
\text { Multibacillary }\end{array}$ & 10 & 200 & $7 \cdot 82^{*} \pm 0.98$ & $2-19$ \\
Controls & 10 & 270 & $11 \cdot 04 \dagger \pm 1 \cdot 76$ & $2-25$ \\
& 10 & 225 & $7 \cdot 16 \pm 0.69$ & $1-17$ \\
\hline
\end{tabular}

* Non-significant in Student's 't' test $P>0.05$.

$\dagger$ Significant in Student's 't' test $P<0.001$.

\section{Discussion}

The commonly used drug in leprosy therapy, dapsone $\left(4,4^{\prime}\right.$ diaminodiphenylsulfone, DDS), is known to cause chromosomal damage when added directly to lymphocyte cultures of healthy individuals. ${ }^{8}$ However, it was not possible to detect such an increased frequency of aberrations when chromosomal preparations from leprosy patients undergoing dapsone therapy were analysed. ${ }^{9}$ These controversial results from previous studies indicated the need to investigate the possible causative agents separately to demonstrate each factor in the aetiology of chromosome aberrations. The present study, is, to our knowledge, the first documentation of the observation that significantly higher frequencies of structural chromosome aberrations and SCEs occur in untreated leprosy patients and implies that, bacteria like $M$. leprae may cause genetic damage. This is in good agreement with the earlier observations that Mycoplasmas can induce chromosome aberrations ${ }^{19-21}$ and $\mathrm{SCEs}^{22}$ by infecting lymphocytes in cultures. Furthermore, the increased frequency of chromosomal aberrations and SCEs in the multibacillary group relative to the paucibacillary group and the controls, as well as the significant increase of chromosomal aberrations but not of SCEs in the paucibacillary group compared to that of controls, demonstrates the possible existence of association between the severity of this disease (i.e. form of leprosy) and proportional increase in the extent of DNA damage. The presence of chromatid type aberrations is greater than the chromosome type, indicating that the damage might have occurred during the S-phase (DNAsynthesis) or the $G_{2}$ period of the cell cycle. This also suggests that the agents like bacteria are effective during synthetic phase of the cell cycle. 
The role of DDS as a mutagenic agent is not ruled out by our study. In fact, it is possible that these 2 agents may act synergestically in treated patients, but that their mechanism of action may be different.

At the present time, the mechanism of action of $M$. leprae in causing chromosome aberrations and SCEs is not clearly understood. Several factors may be involved, resulting in, increased frequency of SCEs. One of the important factors is variation in lymphocyte subpopulations and there is a clear evidence for differences in SCE frequencies in different subpopulations of lymphocytes. ${ }^{11,23}$

The multibacillary patients have a depressed cell-mediated immunity (CMI). ${ }^{24,25}$ This depression in CMI could be due to the functionally deficient or functionally def ective T-lymphocytes and the changes among T-lymphocyte subsets. ${ }^{26}$ So the presumably altered lymphocyte profile in multibacillary patients might be considered as one of the causes for the increased basal levels of SCEs in lymphocytes. Nevertheless, it is known that certain bacterial enzymes can act as DNases and may induce lesions in host cell DNA. ${ }^{27} \mathrm{~A}$ detailed in vitro study using $M$. leprae may throw light on the mechanism of bacterial action on chromosomes.

\section{Acknowledgments}

This work was financially supported by Rameshwardas Birla Smarak Kosh, Bombay. We thank Dr P Neelamkavil, the staff of the department of Dermatology, St John's Medical College and the staff of Sumana Halli Rehabilitation Centre, Bangalore, for providing blood samples of the patients. We gratefully acknowledge the advice and critical review of the study proposal by Dr B C Das.

\section{References}

${ }^{1}$ Hamper B, Ellison SA. Chromosomal aberrations induced by an animal virus. Nature, 1961; 192: 145-7.

2 Vogt N, Dulbecco R. Studies in the neoplastic transformation of hamster embryo cells by Polyoma virus. Proc Natl Acad Sci, 1963; 49: 171-9.

${ }^{3}$ Nicholas WW. Studies on the role of viruses in somatic mutations. Hereditas, 1966: 55: 1-27.

4 Nicholas WW, Levan A, Aula P, Norrby E. Extreme chromosome breakage induced by measles virus in different in vitro systems. Hereditas, 1964; 51: 380-2.

5 Brown RL, Crossen PE. Increased incidence of sister chromatid exchanges in Rauscher Leukemia-virus inf ected mouse embryo fibroblasts. Exp Cell Res, 1976; 103: 418-20.

6 Kato N, Sandberg AA. Effects of herpes simplex virus on sister chromatid exchanges and chromosome abnormalities in human diploid fibroblasts. Exp Cell Res, 1976; 103: 418-20.

${ }^{7}$ Kurvink K, Bloomfield CD, Keenen KM, Lavitis CJ. Sister chromatid exchanges in lymphocytes from patients with malignant lymphomas. Hum Genet, 1978; 44: 137-44.

8 Beiguelman B, Pisani RCB, El-Guindy MM. In vitro effects of dapsone on human chromosomes. Int J Lepr, 1975; 43: 41-4.

9 Beiguelman B, Pisani RCB. Chromosomal aberrations in leukocyte metaphases of leprosy patients under dapsone therapy. Hansenol Int, 1976; 1: 53-60.

${ }^{10}$ Hackel C, Beiguelman B. Chromosomal aberrations in cultures of skin fibroblasts of leprosy patients. Int $J$ Lepr, 1985; 53: 533-9.

11 Santesson B, Lindahl-Kiessling K, Mattsson A. SCE in B and T lymphocytes. Possible implications for Bloom's syndrome. Clin Genet, 1979; 16: 133-5.

12 Sharma T, Das B.C. Culture media and species-related variations in the requirement of 5-bromodeoxyuridine for differential sister chromatid staining. Mutat Res, 1981: 81: 357-64.

13 Ridley DS, Jopling WH. Classification of leprosy according to immunity of five group system. Int J Lepr, 1966; 34: 255-73.

14 Arakaki DT, Sparkes RS. Microtechnique for culturing leukocytes from whole blood. Cytogenet Cell Genet, 1963; 2: 57-60.

15 Perry P, Wolff S. New Giemsa method for the differential staining of sister chromatids. Nature, 1974; 251: 156-8. 
16 Goto K, Akematsu T, Shimazu H, Sugiyama T. Simple differential Giemsa staining of sister chromatids after treatment with photosensitive dyes and exposure to light and the mechanism of staining. Chromosoma, 1975; 53: 223-30.

17 Das BC, Sharma T. The fate of X-ray-induced chromosome aberrations in blood lymphocytes culture. Mutat Res, 1987; 176: 93-104.

18 ISCN: An International System for human cytogenetic nomenclature. Cytogenet Cell Genet, 1978; 21: 309404.

19 Aula P, Nichols WW. The cytogenetic effects of mycoplasma in human leukocyte cultures. J Cell Physiol, 1967; 70: 281-90.

20 Paton GR, Jacobs JP, Perkins FT. Chromosome changes in human diploid cell cultures infected with mycoplasma. Nature, 1965; 207: 43-5.

${ }^{21}$ Kundsin RB, Ampola M, Streeter S, Neurath P. Chromosome aberrations induced by T strain mycoplasmas. J Med Genet, 1971; 8: 181-7.

22 Ito-Kuwa S, Aoki Shigeji. Increased sister chromatid exchanges in human lymphocyte cultures inf ected with mycoplasma. Microbiol Immunol, 1984; 28: 893-901.

23 Santesson B. Different baseline sister chromatid exchange levels in density fractionated human lymphocytes. Hum Genet, 1986; 73: 114-18.

24 Jopling WH. Handbook of Leprosy. London: William Heinemann Medical Books Ltd., 1978.

25 Bryceson A, Pfaltzgraff RE. Leprosy. Edinburgh: Churchill Livingstone, 1979.

26 Rea TH. Supressor cell activity and phenotypes in the blood or tissues of patients with leprosy. Clin exp Immunol, 1983; 54: 298-304.

27 Slack JM, Synder IS, Bacteria and human disease. Chicago, London: Year Book Medical Publishers Inc., 1978, 1-22.

\section{TEACHING MATERIALS AND SERVICES}

\section{Gandhi Memorial Leprosy Foundation; training schedule}

We are grateful to the Director, Mr S P Tare, for sending information about training courses in 1988. They are essentially under four main headings: paramedical workers (4 months); health education ( 2 months); medical officers (6 weeks); statistics (21 working days). These take place in Wardha and Chilakalapalli (Andhra Pradesh). Further information; Director, GMLF, Hindinagar Wardha, 442103, India.

\section{Clinical leprosy by V N Sehgal}

We have just received a copy of this book from India, an illustrated second edition published by Jaypee Brothers, Medical Publishers, P.O. Box 7193, G-16, EMCA House, 23/23B, Ansari Road, Daryaganj, New Delhi 110002 , Price 45 rupees. The International Journal of Leprosy reviewed it as follows: 'The text of this book deals with different clinical facets of the disease, which are essential for the undergraduate and also postgraduate students. They are based on didactic lectures and clinical demonstration on leprosy, which the author has been imparting to students for the past two decades. . . It may be usef ul also to practising physicians and leprosy field workers in developing countries in particular.'

\section{KLEP; Karigiri Leprosy Education Programme}

We have just received from Dr C J G Chacko, Head, Branch of Laboratories, SLRTC, Karigiri 632 106, India, this excellent 'Technical Manual for Smear Personnel'. It is, '. . . a step-by-step instruction manual, written primarily for technicians and paramedical workers in developing countries where leprosy is endemic. The contents of the book has arisen out of interactions we have had with technicians and trainees, who face many problems in control programmes without adequate guidance and support. The book has been written in simple English (the vocabulary is Grade I in Chapters 1 and 2) since the majority of our target audience have difficulty in comprehending English. In addition, a page-by-page glossary is provided at the end of the book.'

(To our knowledge, this is the fift hublication on the subject of slit-skin smears in leprosy in recent years and the time may be approaching for a 'consensus' meeting. In that case, this version form KLEP merits serious attention: it may be one of the best so far produced.-Editor.)

\section{TALC teaching set; leprosy in childhood}

Since its development in the early 1970 s, this set of 24 colour transparencies on leprosy, accompanied by a written description and questionnaire, has sold 5469 copies. A folow-up analysis some years ago indicated that each set is seen by about 80 students in the first year af ter its receipt. It is now to be revised and brought up to date and a new version should be available later in 1988, or early in 1989. 


\section{TALC; Primary eye care}

Also from TALC (Teaching Aids at Low Cost, P.O. Box 49, St Albans, Herts AL1 4AX, England), this set of colour transparencies has been produced by Victoria Sheffield of Helen Keller International Incorporated, New York, and Felicity Savage King of the Institute of Child Health in London. There are 24 colour transparencies of high quality, accompanied by a written text, including notes for teachers. There is also a full size ' $\mathrm{C}$ chart' for testing vision and a useful glossary.

These sets are only two examples of a wide range of teaching-learning colour transparency sets available from TALC on almost every important aspect of medical care in developing countries, with particular emphasis on childhood. Full information about costs, postage, etc, can be obtained from the above address. Most sets with text cost only a few pounds sterling and there are considerable reductions for applicants working in developing countries. The quality of transparencies and written information is unif ormly high and thesesets, by any standards, are extremely good value for money.

\section{OXFAM; packs of teaching-learning materials on leprosy}

These packs of 8 items of teaching-learning material (English language) are still available from the Health Unit, OXFAM, 274 Banbury Road, Oxf ord OX2 7DZ, England, but stocks are running low; only about 100 remain. Since this service started in 1982, over 800 packs have been distributed, but there is now evidence that demand is falling and when present stocks are sold out, distribution will stop, probably towards the end of 1988 .

\section{Dermatology of black skin. Pocket atlas for dermatologists, 1986}

This is a small, pocket size, hardback book of 111 pages, plus index, '. . not just intended for dermatologists, but for all medical and paramedical staff looking after black patients'. The object is to describe and illustrate the clinical signs of skin diseases on the black skin and to emphasize the differences, compared to white skin. Inf ectious and parasitic disease have been omitted on the grounds that their features would require a separate volume, but an exception has been made in the case of leprosy, because of its obvious importance in black patients.

The booklet has been translated from the French by a consultant dermatologist, Dr Andrew Pembroke, King's College Hospital, London. The authors are André Bassett (Strasbourg, France), Bernard Liautaud (Port-au-Prince, Haiti) and Bassirau Ndiaye (Dakar, Senegal). Published in England by Oxford University Press. The section on leprosy has some excellent clinical pictures and is for the most part accurate and helpf ul in its text. However, there are misleading statements about the distribution of leprosy in the world on page 76 and the WHO drug regimens on page 77, where it is stated that the regimens are based "on combination therapy with rif ampicin, ethionamide and clofazimine,' (they are in fact, based on the use of dapsone and rif ampicin for paucibacillary cases and on dapsone, rif ampicin and clofazimine for multibacillary cases, ethionamide being recommended in the treatment of multibacillary leprosy only in those cases who cannot tolerate or accept clof azimine). The patient in Fig 118 is described as 'untreated lepromatous leprosy' but in fact the appearances are strongly suggestive of the histoid form, and the statement relating alopecia to leonine facies in the same Figure is misleading. Despite these criticisms on one subject, the book is likely to be of practical value and the illustrations are of very high quality. Apply: any medical bookseller, or branch of Oxford University Press, Oxford, New York, Delhi, Singapore, Cape Town.

\section{Dermatology. Colour aids. Churchill Livingstone, 1987}

This is a strongly bound paperback, published by Churchill Livingstone and written by dermatologists (J D Wilkinson, S Shaw and D A Fenton) from High Wycombe and London. It has 153 pages and no fewer than 245 colour pictures of commonly occurring and important dermatological conditions, mainly UK, Europe and America-orientated, without attempting to include tropical dermatology. The explanatory text is brief but informative. The pictures are of unusually high quality. Although virtually all the patients are light-skinned, this booklet could be of practical value to doctors and paramedical workers in many parts of the world; the pictures are so well chosen that they have an almost instant message which should greatly assist diagnosis and management. Apply: any medical bookseller or branch of Churchill Livingstone: Edinburgh, London, Melbourne \& New York.

\section{International courses on leprosy, Fontilles, Spain}

We are grateful to the Medical Director, Dr Terencio de las Aguas, Sanatorio de Fontilles, Fontilles, Alicante, Spain for sending details of the XXV International Course on Leprology for Doctors, organized by the Sanatorio San Francisco de Bor ja de Fontilles and Sovereign Military Order of Malta, with the collaboration of the School of Dermatology in the University of Valencia and the Ministry of Health. The course runs from 7 to 12 November 1988. Another course for health assistants ('auxiliares sanitarios') will be held from 10 to 29 October 1988. Apply to the Director as above. 